\title{
Application of Gaussian Bayes classifier to differentiate chlorine-based chemical agents
}

Dongwon Lee

Brian Bucher

Ken Krebs

Ed Seabury

Jason Wharton

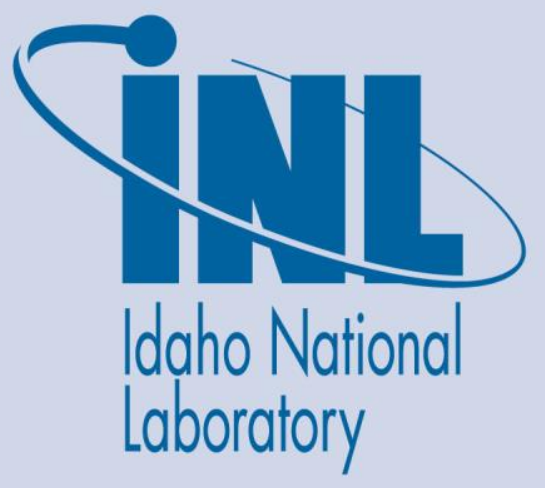

April 7, 2020

The INL is a U.S. Department of Energy National Laboratory operated by Battelle Energy Alliance 


\section{DISCLAIMER}

This information was prepared as an account of work sponsored by an agency of the U.S. Government. Neither the U.S. Government nor any agency thereof, nor any of their employees, makes any warranty, expressed or implied, or assumes any legal liability or responsibility for the accuracy, completeness, or usefulness, of any information, apparatus, product, or process disclosed, or represents that its use would not infringe privately owned rights. References herein to any specific commercial product, process, or service by trade name, trade mark, manufacturer, or otherwise, does not necessarily constitute or imply its endorsement, recommendation, or favoring by the U.S. Government or any agency thereof. The views and opinions of authors expressed herein do not necessarily state or reflect those of the U.S. Government or any agency thereof. 


\title{
Application of Gaussian Bayes classifier to differentiate chlorine-based chemical agents
}

\author{
D. Lee \\ B. Bucher \\ K. Krebs \\ E. Seabury \\ J. Wharton
}

April 7, 2020

\author{
Idaho National Laboratory \\ Nuclear Nonproliferation Division \\ Idaho Falls, Idaho 83415
}

http://www.inl.gov

Prepared for the

U.S. Department of Energy

Office of National Nuclear Security Administration

Under DOE Idaho Operations Office

Contract DE-AC07-05ID14517 



\begin{abstract}
The Portable Isotopic Neutron Spectroscopy (PINS) is a commercialized system developed by Idaho National Laboratory (INL) to examine chemical warfare agents (CWA) non-destructively, utilizing Prompt Gamma Neutron Activation Analysis (PGNAA) techniques. The PINS system takes advantage of a high-resolution gamma-ray spectrum from a mechanically-cooled high-purity germanium (HPGe) detector. One of the difficult technical challenges is to discriminate the chlorine-based chemical agents. Especially, CN, CNB, CNS and CG have similar chemical compositions to make it hard to discriminate them with a higher confidence. Current identification algorithms for PINS systems with 252-Cf sources have been improved and updated continuously as more field data became available, and new algorithms was studied to complement the current algorithms by adopting the Gaussian Bayes classifier. These new algorithms were intended to be applied to a subset of chlorine-based chemical agents, and their main goal is discriminate $\mathrm{CN}, \mathrm{CNB}, \mathrm{CNS}$ and $\mathrm{CG}$ with their ratios of the chlorine neutron inelastic $1763 \mathrm{keV}$ peak to the chlorine thermal neutron capture $1959 \mathrm{keV}$ peak, which is referred to as the " $\mathrm{Cl} \mathrm{i/c"} \mathrm{or} \mathrm{"clic"} \mathrm{ratio} \mathrm{in}$ this study. The $\mathrm{Cl} \mathrm{i/c}$ ratios were assumed to follow Gaussian distributions with the means and the standard deviations unique to their corresponding chemical agents. The prior probabilities of these four chemical agents were optimized with a collection of field data to achieve the best performance in terms of precision or positive predictive value (PPV). Finally, their posterior probabilities as functions of the $\mathrm{Cl} \mathrm{i/c}$ ratio were implemented in the current version of PINS analysis software in order to be tested with more field data.
\end{abstract}




\section{CONTENTS}

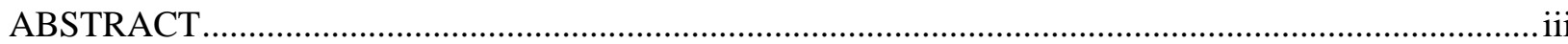

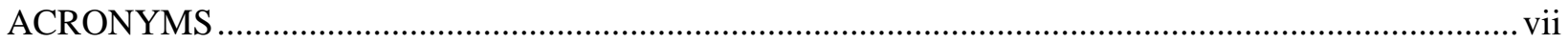

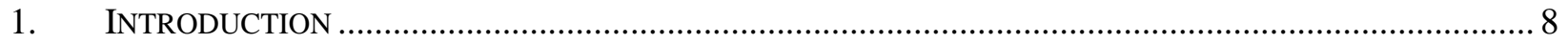

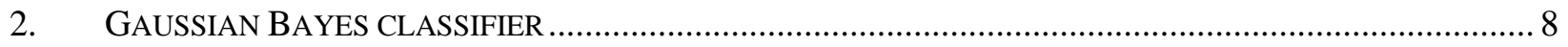

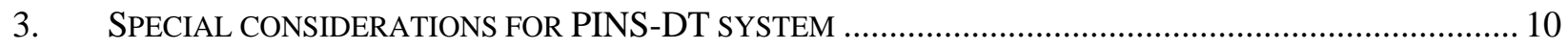

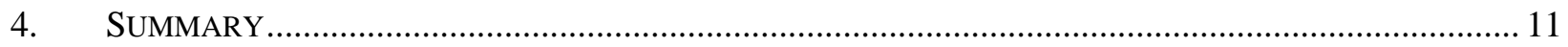

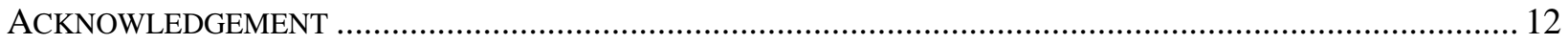

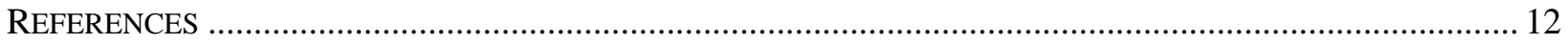

\section{FIGURES}

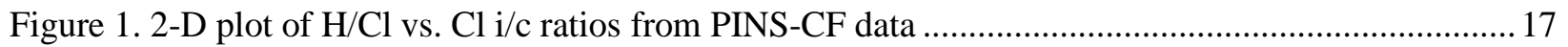

Figure 2. $\mathrm{Cl}$ i/c ratio values fitted with a normalized Gaussian distribution........................................... 17

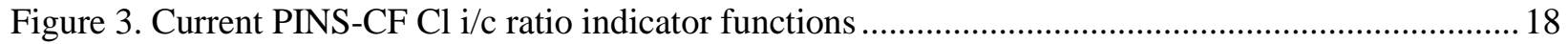

Figure 4. Newly proposed PINS-CF system's $\mathrm{Cl}$ i/c ratio indicator functions with equal prior

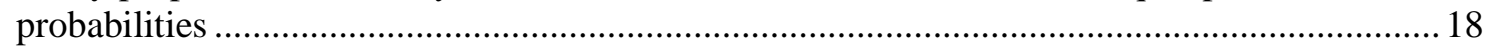

Figure 5. Test results with three different sets of prior probabilities for CN, CNB, CNS and CG............ 19

Figure 6. Newly proposed PINS-CF system's $\mathrm{Cl}$ i/c ratio indicator functions ........................................20

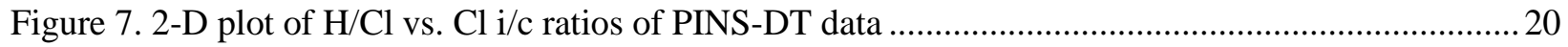

Figure 8. Newly proposed PINS-DT system's $\mathrm{Cl}$ i/c ratio indicator functions.........................................21

\section{TABLES}

Table 1. Chemcial compositions of the chlorine-based chemcial agents................................................ 13

Table 2. Calculated posterior probabilities of the four chemical agents for PINS-CF system ................... 13

Table 3. Identifications of the 2018 blind test data with default and modified CF formulae .................... 14

Table 4. Calculated posterior probabilities of the four chemical agents for PINS-DT system.................. 15

Table 5. Identifications of the 2018 blind test data with default and modified DT formulae..................... 16 


\section{ACRONYMS}

$\begin{array}{ll}\text { Cl i/c } & \text { Chlorine inelastic-to-capture } \\ \text { CG } & \text { Phosgene, choking agent } \\ \text { CN } & \text { Riot control/tear agent } \\ \text { CNB } & \text { Riot control/tear agent } \\ \text { CNS } & \text { Riot control/tear agent } \\ \text { CWA } & \text { Chemical Warfare Agents } \\ \text { D-D } & \text { Deuterium-Deuterium } \\ \text { D-T } & \text { Deuterium-Tritium } \\ \text { HN-3 } & \text { Nitrogen mustard-3, blister agent } \\ \text { CK } & \text { Blood agent } \\ \text { HPGe } & \text { High purity germanium } \\ \text { INL } & \text { Idaho National Laboratory } \\ \text { PGNAA } & \text { Prompt Gamma Neutron Activation Analysis } \\ \text { PINS } & \text { Portable Isotopic Neutron Spectroscopy } \\ \text { PINS+ } & \text { Portable Isotopic Neutron Spectroscopy identification software } \\ \text { PINS-CF } & \text { Portable Isotopic Neutron Spectroscopy system with a 252-Cf source } \\ \text { PINS-DT } & \text { Portable Isotopic Neutron Spectroscopy system with a D-T neutron generator } \\ \text { PPV } & \text { Positive Prediction Value } \\ \text { PS } & \text { Chloropicrin }\end{array}$




\section{Application of Gaussian Bayes classifier to differentiate chlorine- based chemical agents}

\section{INTRODUCTION}

$\mathrm{CN}, \mathrm{CNB}, \mathrm{CNS}$ and CG have similar chemical compositions as summarized in Table $\mathbf{1}$ and their differences in the neutron-induced gamma-ray spectra are very subtle to distinguish one from the other [1]. Previous research efforts to improve PINS-CF algorithms also identified that discrimination of these four chemical agents are quite challenging task to achieve [2-3]. Nevertheless, chlorine inelastic-tocapture ratio ( $\mathrm{Cl} \mathrm{i} / \mathrm{c}$ or "clic", $\mathrm{Cl} 1763 \mathrm{keV}$ peak area to $\mathrm{Cl} 1959 \mathrm{keV}$ peak area) is considered one of the key indicators to discriminate $\mathrm{CN}, \mathrm{CNB}, \mathrm{CNS}$ and $\mathrm{CG}^{*}$. $\mathrm{Cl}$ i/c ratios versus $\mathrm{H} / \mathrm{Cl}(\mathrm{H} 2223 \mathrm{keV}$ to $\mathrm{Cl}$ $1959 \mathrm{keV}$ ) ratios from a collection of the accumulated PINS-CF data are plotted in Figure 1. It shows that $\mathrm{Cl} \mathrm{i} / \mathrm{c}$ ratio varies from 0.0 to 2.5 , but their differences are not large enough so that their distributions show significant amount of overlaps. $\mathrm{H} / \mathrm{Cl}$ ratio is not very sensitive enough to be a feature to discriminate these four chemical agents with a higher confidence level. However, $\mathrm{Cl} \mathrm{i} / \mathrm{c}$ ratio values form clusters for individual chemical agents although their boundaries are not drawn clearly. Therefore, Bayes' theorem is applied to calculate each chemical agent's likelihood when $\mathrm{Cl} \mathrm{i} / \mathrm{c}$ ratio values are known, assuming $\mathrm{Cl}$ i/c ratio values are described by a Gaussian distribution.

\section{GAUSSIAN BAYES ClASSIFIER}

The first assumption in this study is that measured $\mathrm{Cl} \mathrm{i} / \mathrm{c}$ ratios from one chemical agent can be described by a Gaussian distribution with the mean and the standard deviation unique to the chemical agent. There is no prior study or evidence to support this assumption yet, but a Gaussian distribution explains the behavior of $\mathrm{Cl}$ i/c ratio distribution relatively well, if not perfect, as shown in Figure 2. The second assumption is that each chemical agent has certain prior probability to be found in the field operations. For example, the simplest assumption is that each chemical agent has equal prior probability of 0.25 . As shown in Figure 1, Cl i/c ratios of all four chemical agents are described by Gaussian distributions derived from their corresponding data, respectively. Once a $\mathrm{Cl} \mathrm{i} / \mathrm{c}$ ratio from a unknown spectrum is given, Bayes' theorem is applied to calculate each chemical agent's posterior probability by Eq. (1).

\footnotetext{
* HN-3 and CK are excluded in this study since they are confirmed only when high energy nitrogen peaks are detected in addition to $\mathrm{Cl} \mathrm{i} / \mathrm{c}$ values. Also, PS (chloropicrin) is excluded due to lack of data to be used in this study.
} 


$$
\begin{gathered}
P(C X \mid x)=\frac{P(x \mid C X) P(C X)}{P(x)} \\
=\frac{P(x \mid C X) P(C X)}{P(x \mid C G) P(C G)+P(x \mid C N S) P(C N S)+P(x \mid C N B) P(C N B)+P(x \mid C N) P(C N)}
\end{gathered}
$$

where $x$ is $\mathrm{Cl}$ i/c ratio and $C X$ is either $\mathrm{CN}, \mathrm{CNB}$, CNS or CG. $P(C X)$ and $P(x \mid C X)$ are each chemical agent's prior probability and likelihood, respectively. $P(x \mid C X)$ is given by chemical agent $C X$ 's normalized Gaussian distribution as a function of $\mathrm{Cl}$ i/c ratio $x . P(x \mid C X)$ is the probability that the measured $\mathrm{Cl}$ i/c ratio is $x$ given that the chemical agent is the $C X$.

Figure 3 shows output from the $\mathrm{Cl}$ i/c indicator functions defined in the current PINS-CF algorithms for $\mathrm{CN}, \mathrm{CNB}, \mathrm{CNS}$ and CG. In Figure 4, The posterior probabilities of the four chemical agents calculated by Bayes' theorem in Eq. (1) are plotted with $P(C N)=0.25, P(C N B)=0.25, P(C N S)=0.25$ and $P(C G)=0.25$. Traditionally, PINS algorithms have adopted the indicator function as defined in Eq. (2) to express indicator and penalty functions.

$$
E S(X, Y, Z)=\left\{\begin{array}{cl}
0 & \text { when } X<Y \\
0.5-0.5 \times \cos \left(\frac{\pi(X-Y)}{(Z-Y)}\right) & \text { when } Y \leq X<Z \\
1 & \text { when } X \geq Z
\end{array}\right.
$$

It is inconvenient to use the analytical function as shown in Eq. (1) to use in each chemical agent's formula file. Fortunately, four chemical agents' posterior probabilities can be approximated by the ES functions whose parameter $Y_{C X}$ and $Z_{C X}$ values were selected to match them best. As a result, newly proposed indicator functions of $\mathrm{Cl} \mathrm{i} / \mathrm{c}$ ratio for $\mathrm{CN}, \mathrm{CNB}, \mathrm{CNS}$ and $\mathrm{CG}$ are expressed in the forms given by Eq. (3).

$$
\begin{aligned}
& \text { clic }=C l 1763 \mathrm{keV} \text { net peak area } / \mathrm{Cl} 1959 \mathrm{keV} \text { net peak area } \\
& p C N=1-E S\left(\text { clic, } Y_{C N}, Z_{C N}\right) \\
& p C N B=\text { Const }_{C N B} * E S\left(\text { clic, } Y 1_{C N B}, Z 1_{C N B}\right) *\left(1-E S\left(\text { clic, } Y 2_{C N B}, Z 2_{C N B}\right)\right) \\
& p C N S=\text { Const }_{C N S} * E S\left(\text { clic, } Y 1_{C N S}, Z 1_{C N S}\right) *\left(1-E S\left(\text { clic, } Y 2_{C N S}, Z 2_{C N S}\right)\right) \\
& p C G=E S\left(\text { clic, } Y_{C G}, Z_{C G}\right)-\text { Const }_{C N S} * E S\left(\text { clic, } Y 1_{C N S}, Z 1_{C N S}\right) *\left(1-E S\left(\text { clic, } Y 2_{C N S}, Z 2_{C N S}\right)\right)
\end{aligned}
$$

However, all $Y_{C X}$ and $Z_{C X}$ values vary whenever prior probabilities change. In order to find the best performing indicator functions, three different sets of indicator functions obtained from three different sets of prior probabilities were tested with PINS+ v6.6.0. The four default formula files of CN, CNB, CNS and CG were modified by replacing the current $\mathrm{Cl}$ i/c ratio indicator functions with new ones. Then, 
a total of 57 spectra were analyzed to be identified by PINS+ v6.6.0 as shown in Figure 5. It should be noted that chemical agent PS (chloropicrin) was deactivated in PINS+ v6.6.0. The first table summarizes the analysis results by PINS+ v6.6.0 with the default formula files. The other three tables summarizes the analysis results with modified formula files for different sets of prior probabilities: $[P(C N): P(C N B): P(C N S): P(C G)]=[0.25: 0.25: 0.25: 0.25], \quad[0.1: 0.2: 0.3: 0.4]$ and [0.1:0.1:0.3:0.5], respectively. The set of prior probabilities of [0.1:0.2:0.3:0.4] achieved the highest precisions for all four chemical agents. Therefore, the newly proposed indicator functions are given by Eq. (4).

$$
\begin{aligned}
& \text { clic }=C l 1763 k e V \text { net peak area } / C l 1959 k e V \text { net peak area } \\
& p C N=1-E S(\text { clic, } 0.0633,0.2005) \\
& p C N B=0.9083 * E S(\text { clic }, 0.0644,0.1991) *(1-E S(\text { clic, } 0.2340,0.5173)) \\
& p C N S=0.6400 * E S(\text { clic, } 0.2070,0.5226) *(1-E S(\text { clic, } 0.5393,1.7990)) \\
& p C G=E S(\text { clic, } 0.2033,0.5258)-0.6400 * E S(\text { clic, } 0.2070,0.5226) *(1-E S(\text { clic, } 0.5393,1.7990))
\end{aligned}
$$

The solid lines in Figure 6 are the approximated $P(C X \mid x)$ values calculated by Eq. (4) while the dotted lines are the analytical $P(C X \mid x)$ values given by Eq. (1) with $P(C N)=0.10, P(C N B)=0.20$, $P(C N S)=0.30$ and $P(C G)=0.40$. Finally, the newly proposed $\mathrm{Cl} \mathrm{i} / \mathrm{c}$ ratio indicator functions were tested against the 2018 blind test dataset, and the results are summarized in Table 2 and Table 3. All four chemical agents were correctly identified by the highest $P(C X \mid x)$ values in Table 2 , and analysis results from PINS+ v6.6.0 with the modified formula files are summarized in Table 3. Again, chemical agent PS was deactivated in PINS+ v6.6.0 since identification of PS is beyond the current scope of this study.

\section{SPECIAL CONSIDERATIONS FOR PINS-DT SYSTEM}

PINS-DT system utilizes $14 \mathrm{MeV}$ neutrons from a $\mathrm{D}-\mathrm{T}$ neutron generator, and $\mathrm{Cl} \mathrm{i} / \mathrm{c}$ ratio distributions for $\mathrm{CN}, \mathrm{CNB}, \mathrm{CNS}$ and CG are expected to shift toward higher values than PINS-CF system. This is because inelastic scattering reactions are dominated while thermal neutron capture reactions are suppressed due to much higher neutron energy. A set of indicator functions similar to Eq. (4) were derived in order to handle PINS-DT system separately. It should be noted that $\mathrm{Cl}$ i/c ratio for PINS-DT system was defined differently as given by the first equation in Eq. (5). $\mathrm{Cl}$ i/c ratios versus $\mathrm{H} / \mathrm{Cl}(\mathrm{H} 2223 \mathrm{keV}$ to $\mathrm{Cl} 1959 \mathrm{keV})$ ratios from a collection of 78 PINS-DT spectra are plotted in Figure 7. The solid lines in Figure 8 are the approximated $P(C X \mid x)$ values calculated by Eq. (5) while the dotted lines are the analytical $P(C X \mid x)$ values given by Eq. (1) with $P(C N)=0.10, P(C N B)=0.20, P(C N S)=0.30$ and $P(C G)=0.40$. 


$$
\begin{aligned}
& \text { clic }=\text { Cl } 1763 \mathrm{keV} \text { net peak area } /(C l 1951 \mathrm{keV} \text { net peak area } \times 2 / 3) \\
& p C N=0.2205 *(1-E S(\text { clic, } 0.0000,0.7780))+0.1847 *(1-E S(\text { clic, } 1.5000,3.0000)) \\
& p C N B=0.6704 * E S(\text { clic, }-0.8578,0.7989) *(1-E S(\text { clic, } 1.0497,2.3838)) \\
& p C N S=0.5837 * E S(\text { clic, } 0.5688,2.9675) *(1-E S(\text { clic, } 4.4877,14.0785)) \\
& p C G=E S(\text { clic, } 0.5429,2.8023)-0.5837 * E S(\text { clic, } 0.5688,2.9675) *(1-E S(\text { clic, } 4.4877,14.0785))
\end{aligned}
$$

The newly proposed $\mathrm{Cl}$ i/c ratio indicator functions for PINS-DT system were tested against the 2018 blind test dataset, and the results are summarized in Table $\mathbf{4}$ and Table 5. All four chemical agents were correctly identified by the highest $P(C X \mid x)$ values as shown in Table 4. It is clear that PINS-DT system is less effective than PINS-CF system to differentiate $\mathrm{CN}$ from $\mathrm{CNB}$ due to their large overlap in $\mathrm{Cl} \mathrm{i} / \mathrm{c}$ ratios. Analysis results from PINS+ v6.6.0 with the newly proposed DT formula files are summarized in Table 5. Again, chemical agent PS was deactivated in PINS+ v6.6.0 since identification of PS is beyond the current scope of this study. All three CN cases were misidentified as CNB but CNS identification was improved by the newly proposed indicator functions as is clearly shown in Table $\mathbf{5}$.

\section{SUMMARY}

Gaussian classification was applied to the four chlorine-based chemical agents CN, CNB, CNS and CG. Chlorine $\mathrm{i} / \mathrm{c}$ ratio distribution of each chemical agent was assumed to follow Gaussian distribution, and Bayes' theorem was applied to calculate each chemical agent's posterior probability for a given $\mathrm{Cl} \mathrm{i/c}$ ratio. The set of prior probabilities of $[P(C N): P(C N B): P(C N S): P(C G)]=[0.1: 0.2: 0.3: 0.4]$ was found to be the best performing one after performance evaluation against a collection of 57 PINS-CF spectra of the four chemical agents. New $\mathrm{Cl}$ i/c ratio indicator functions of these four chemical agents were proposed for PINS-CF and PINS-DT systems, respectively. PINS+ v6.6.0 was tested against CF and DT formula files with the newly proposed $\mathrm{Cl} \mathrm{i} / \mathrm{c}$ ratio indicator functions. These new indicator functions improved performance in identifying these four chemical agents compared to the current formulae. This study demonstrated that Gaussian Bayes classifier derived from $\mathrm{Cl}$ i/c ratio distributions could prevent CNS from being misidentified as CG effectively. 


\section{ACKNOWLEDGEMENT}

PINS research and development at Idaho National Laboratory is supported by the U.S. Army Recovered Chemical Materiel Directorate and the Joint Program Executive Office for Chemical, Biological, Radiological, and Nuclear Defense, under U.S. Department of Energy Field Office, Idaho contract number DE-AC07-05ID14517.

\section{REFERENCES}

[1] A.J. Caffrey, et al., "Chemical Warfare Agent and High Explosive Identification by Spectroscopy of Neutron-induced Gamma-Rays", IEEE Trans. Nucl. Sci, 39, pp 1422-1426, (1992).

[2] D. Lee, et al., "Application of Multivariate Data Analysis Techniques for the Portable Isotopic Neutron Spectroscopy System", IEEE NSS-MIC conference, Atlanta (2017)

[3] D. Lee, Application of artificial neural network to prompt gamma neutron activation analysis for chemical warfare agents identification, Idaho National Laboratory report INL/EXT-19-55616 (2019) 
Table 1. Chemcial compositions of the chlorine-based chemcial agents CN, CNB, CNS and CG.

Chemical agent

$\mathrm{CN}$ (chloroacetophenone, riot control/tear agent)

$\mathrm{CNB}(\mathrm{CN}+$ carbon tetrachloride + benzene $)$

$\mathrm{CNS}(\mathrm{CN}+$ chloroform + chloropicrin $)$

$\mathrm{CG}$ (phosgene, choking agent)
Chemical formula

$\mathrm{C}_{8} \mathrm{H}_{7} \mathrm{ClO}$

$\mathrm{C}_{8} \mathrm{H}_{7} \mathrm{ClO}+\mathrm{CCl}_{4}+\mathrm{C}_{6} \mathrm{H}_{6}$

$\mathrm{C}_{8} \mathrm{H}_{7} \mathrm{ClO}+\mathrm{CHCl}_{3}+\mathrm{CCl}_{3} \mathrm{NO}_{2}$

$\mathrm{COCl}_{2}$

Table 2. Calculated posterior probabilities of the four chemical agents at given $\mathrm{Cl} \mathrm{i} / \mathrm{c}$ ratios for PINS-CF system.

\begin{tabular}{|c|c|c|c|c|c|}
\hline $\begin{array}{c}2018 \text { Blind test } \\
\text { true ID }\end{array}$ & Cl i/c ratio, $x$ & $P(C N \mid x)$ & $P(C N B \mid x)$ & $P(C N S \mid x)$ & $P(C G \mid x)$ \\
\hline CN & 0.0890 & $\mathbf{0 . 9 1 5 6}$ & 0.0727 & 0.0000 & 0.0000 \\
\hline CN & 0.1269 & $\mathbf{0 . 5 5 7 2}$ & 0.4024 & 0.0000 & 0.0000 \\
\hline CN & 0.1160 & $\mathbf{0 . 6 7 7 5}$ & 0.2912 & 0.0000 & 0.0000 \\
\hline CNB & 0.2355 & 0.0000 & $\mathbf{0 . 9 0 8 2}$ & 0.0129 & 0.0117 \\
\hline CNB & 0.2068 & 0.0000 & $\mathbf{0 . 9 0 8 3}$ & 0.0000 & 0.0003 \\
\hline CNB & 0.2269 & 0.0000 & $\mathbf{0 . 9 0 8 3}$ & 0.0063 & 0.0069 \\
\hline CNB & 0.1777 & 0.0666 & $\mathbf{0 . 8 5 2 8}$ & 0.0000 & 0.0000 \\
\hline CNB & 0.1954 & 0.0033 & $\mathbf{0 . 9 0 6 6}$ & 0.0000 & 0.0000 \\
\hline CNS & 0.8658 & 0.0000 & 0.0000 & $\mathbf{0 . 5 3 9 6}$ & 0.4604 \\
\hline CNS & 0.8006 & 0.0000 & 0.0000 & $\mathbf{0 . 5 7 4 4}$ & 0.4256 \\
\hline CNS & 0.8446 & 0.0000 & 0.0000 & $\mathbf{0 . 5 5 1 6}$ & 0.4484 \\
\hline CNS & 0.7863 & 0.0000 & 0.0000 & $\mathbf{0 . 5 8 1 2}$ & 0.4188 \\
\hline CNS & 0.8347 & 0.0000 & 0.0000 & $\mathbf{0 . 5 5 7 0}$ & 0.4430 \\
\hline CNS & 0.8569 & 0.0000 & 0.0000 & $\mathbf{0 . 5 4 4 7}$ & 0.4553 \\
\hline CNS & 0.7196 & 0.0000 & 0.0000 & $\mathbf{0 . 6 0 8 2}$ & 0.3918 \\
\hline CG & 1.4764 & 0.0000 & 0.0000 & 0.0981 & $\mathbf{0 . 9 0 1 9}$ \\
\hline CG & 1.3599 & 0.0000 & 0.0000 & 0.1734 & $\mathbf{0 . 8 2 6 6}$ \\
\hline CG & 1.6980 & 0.0000 & 0.0000 & 0.0101 & $\mathbf{0 . 9 8 9 9}$ \\
\hline CG & 1.5127 & 0.0000 & 0.0000 & 0.0781 & $\mathbf{0 . 9 2 1 9}$ \\
\hline CG & 1.4169 & 0.0000 & 0.0000 & 0.1346 & $\mathbf{0 . 8 6 5 4}$ \\
\hline CG & 1.5283 & 0.0000 & 0.0000 & 0.0702 & $\mathbf{0 . 9 2 9 8}$ \\
\hline CG & 1.8700 & 0.0000 & 0.0000 & 0.0000 & $\mathbf{1 . 0 0 0 0}$ \\
\hline & & & & & \\
\hline & & & & \\
\hline
\end{tabular}


Table 3. Identifications of the 2018 blind test data by PINS+ v6.6.0 with default CF formulae (the $3^{\text {rd }}$ column) and with the newly proposed PINS-CF $\mathrm{Cl} \mathrm{i} / \mathrm{c}$ ratio indicator functions (the $4^{\text {th }}$ column). The shaded rows are the cases correctly identified after implementing the newly proposed PINC-CF indicator functions in PINS+.

\begin{tabular}{|c|c|c|c|}
\hline True ID & Run name & $\begin{array}{c}\text { PINS+ v6.6.0 } \\
\text { default CF formulae }\end{array}$ & $\begin{array}{c}\text { PINS+ v6.6.0 w/ } \\
\text { modified CF formulae }\end{array}$ \\
\hline CG & BT18-001_P2_20Jul18_009 & $\mathrm{CG}$ & $\mathrm{CG}$ \\
\hline $\mathrm{CG}$ & BT18-006_P2_23Jul18_012 & CG & CG \\
\hline $\mathrm{CG}$ & BT18-009_P22_10Aug18_003 & CG & CG \\
\hline CNS & BT18-011_P2_24Jul18_003 & $\times \mathrm{CG}$ & $\checkmark \mathrm{CNS}$ \\
\hline $\mathrm{CG}$ & BT18-015_P2_25Jul18_003 & CG & CG \\
\hline $\mathrm{CG}$ & BT18-018_P2_26Jul18_012 & CG & CG \\
\hline CNS & BT18-019_P2_26Jul18_003 & CNS & $\mathrm{CNS}$ \\
\hline $\mathrm{CG}$ & BT18-023_P2_27Jul18_003 & $\mathrm{CG}$ & $\mathrm{CG}$ \\
\hline CG & BT18-028_P2_30Jul18_006 & CG & CG \\
\hline $\mathrm{CNS}$ & BT18-032_P2_31Jul18_006 & $\times \mathrm{CG}$ & $\checkmark \mathrm{CNS}$ \\
\hline $\mathrm{CNB}$ & BT18-034_P2_01Aug18_012 & $\mathrm{CNB}$ & $\mathrm{CNB}$ \\
\hline CNS & BT18-037_P2_02Aug18_009 & $\times \mathrm{CG}$ & $\checkmark \mathrm{CNS}$ \\
\hline $\mathrm{CN}$ & BT18-051_P2_07Aug18_003 & $\mathrm{CN}$ & $\mathrm{CN}$ \\
\hline CNS & BT18-059_P22_09Aug18_003 & CNS & CNS \\
\hline CNS & BT18-064_P22_23Aug18_006 & $\times \mathrm{CG}$ & $\checkmark \mathrm{CNS}$ \\
\hline $\mathrm{CNB}$ & BT18-065_P22_14Aug18_009 & $\mathrm{CNB}$ & $\mathrm{CNB}$ \\
\hline $\mathrm{CNS}$ & BT18-071_P22_15Aug18_003 & $\mathrm{CNS}$ & $\mathrm{CNS}$ \\
\hline $\mathrm{CNB}$ & BT18-073_P22_16Aug18_009 & $\mathrm{CNB}$ & $\mathrm{CNB}$ \\
\hline $\mathrm{CN}$ & BT18-075_P22_16Aug18_003 & $\mathrm{CN}$ & $\mathrm{CN}$ \\
\hline $\mathrm{CNB}$ & BT18-078_P22_17Aug18_012 & $\mathrm{CNB}$ & $\mathrm{CNB}$ \\
\hline $\mathrm{CN}$ & BT18-086_P22_21Aug18_012 & $\mathrm{CN}$ & $\mathrm{CN}$ \\
\hline $\mathrm{CNB}$ & BT18-089_P22_24Aug18_009 & $\mathrm{CNB}$ & $\mathrm{CNB}$ \\
\hline
\end{tabular}


Table 4. Calculated posterior probabilities of the four chemical agents at given $\mathrm{Cl}$ i/c ratios for PINS-DT system.

\begin{tabular}{|c|c|c|c|c|c|}
\hline $\begin{array}{c}2018 \text { Blind test } \\
\text { true ID }\end{array}$ & + Cl i/c ratio, $x$ & $P(C N \mid x)$ & $P(C N B \mid x)$ & $P(C N S \mid x)$ & $P(C G \mid x)$ \\
\hline CN & 0.2548 & 0.3518 & $\mathbf{0 . 5 1 9 1}$ & 0.0000 & 0.0000 \\
\hline CN & 0.3452 & 0.3144 & $\mathbf{0 . 6 4 7 9}$ & 0.0000 & 0.0000 \\
\hline CN & 0.3056 & 0.3314 & $\mathbf{0 . 6 1 2 5}$ & 0.0000 & 0.0000 \\
\hline CNB & 1.4865 & 0.1847 & $\mathbf{0 . 5 0 7 9}$ & 0.1866 & 0.1855 \\
\hline CNB & 0.8249 & 0.1847 & $\mathbf{0 . 6 5 1 8}$ & 0.0163 & 0.0217 \\
\hline CNB & 1.1096 & 0.1847 & $\mathbf{0 . 6 5 1 1}$ & 0.0702 & 0.0772 \\
\hline CNB & 1.1742 & 0.1847 & $\mathbf{0 . 6 4 3 9}$ & 0.0870 & 0.0936 \\
\hline CNB & 1.1198 & 0.1847 & $\mathbf{0 . 6 5 0 5}$ & 0.0727 & 0.0797 \\
\hline CNS & 3.3150 & 0.0000 & 0.0000 & $\mathbf{0 . 5 8 3 7}$ & 0.4163 \\
\hline CNS & 3.1468 & 0.0000 & 0.0000 & $\mathbf{0 . 5 8 3 7}$ & 0.4163 \\
\hline CNS & 5.8614 & 0.0000 & 0.0000 & $\mathbf{0 . 5 5 4 6}$ & 0.4454 \\
\hline CNS & 4.3929 & 0.0000 & 0.0000 & $\mathbf{0 . 5 8 3 7}$ & 0.4163 \\
\hline CNS & 5.9153 & 0.0000 & 0.0000 & $\mathbf{0 . 5 5 2 3}$ & 0.4477 \\
\hline CNS & 3.7696 & 0.0000 & 0.0000 & $\mathbf{0 . 5 8 3 7}$ & 0.4163 \\
\hline CNS & 3.2664 & 0.0000 & 0.0000 & $\mathbf{0 . 5 8 3 7}$ & 0.4163 \\
\hline CG & 12.5541 & 0.0000 & 0.0000 & 0.0356 & $\mathbf{0 . 9 6 4 4}$ \\
\hline CG & 7.4203 & 0.0000 & 0.0000 & 0.4590 & $\mathbf{0 . 5 4 1 0}$ \\
\hline CG & 8.0366 & 0.0000 & 0.0000 & 0.4077 & $\mathbf{0 . 5 9 2 3}$ \\
\hline CG & 8.5538 & 0.0000 & 0.0000 & 0.3609 & $\mathbf{0 . 6 3 9 1}$ \\
\hline CG & 7.0379 & 0.0000 & 0.0000 & 0.4876 & $\mathbf{0 . 5 1 2 4}$ \\
\hline CG & 9.6856 & 0.0000 & 0.0000 & 0.2535 & $\mathbf{0 . 7 4 6 5}$ \\
\hline CG & 10.6235 & 0.0000 & 0.0000 & 0.1678 & $\mathbf{0 . 8 3 2 2}$ \\
\hline & & & & & \\
\hline
\end{tabular}

\footnotetext{
${ }^{\dagger}$ It should be noted that $\mathrm{Cl} \mathrm{i} / \mathrm{c}$ ratios in this table were calculated by the equation given in Eq. (5), which is different from the one for PINS-CF system
} 
Table 5. Identifications of the 2018 blind test data by PINS+ v6.6.0 with default DT formulae (the $3^{\text {rd }}$ column) and with the newly proposed PINS-DT $\mathrm{Cl}$ i/c ratio indicator functions (the $4^{\text {th }}$ column). The shaded rows are the cases correctly identified after implementing the newly proposed PINC-DT indicator functions in PINS+.

\begin{tabular}{|c|c|c|c|}
\hline True ID & Run name & $\begin{array}{c}\text { PINS+ v6.6.0 } \\
\text { default DT formulae } \\
\end{array}$ & $\begin{array}{c}\text { PINS+ v6.6.0 w/ } \\
\text { modified DT formulae }\end{array}$ \\
\hline CG & BT18-001_P2_20Jul18_009 & $\mathrm{CG}$ & CG \\
\hline $\mathrm{CG}$ & BT18-006_P2_23Jul18_012 & $x \mathrm{HD}$ & $x \mathrm{HD}$ \\
\hline $\mathrm{CG}$ & BT18-009_P22_10Aug18_003 & $\times \mathrm{HD}$ & $\times$ HD \\
\hline CNS & BT18-011_P2_24Jul18_003 & $x \mathrm{CG}$ & $\checkmark \mathrm{CNS}$ \\
\hline $\mathrm{CG}$ & BT18-015_P2_25Jul18_003 & $\times \mathrm{CNS}$ & $\times \mathrm{CNS}$ \\
\hline $\mathrm{CG}$ & BT18-018_P2_26Jul18_012 & CG & CG \\
\hline $\mathrm{CNS}$ & BT18-019_P2_26Jul18_003 & CNS & $\mathrm{CNS}$ \\
\hline $\mathrm{CG}$ & BT18-023_P2_27Jul18_003 & $x \mathrm{HD}$ & $x \mathrm{HD}$ \\
\hline $\mathrm{CG}$ & BT18-028_P2_30Jul18_006 & $\times \mathrm{CNS}$ & × Unknown \\
\hline $\mathrm{CNS}$ & BT18-032_P2_31Jul18_006 & $\times \mathrm{AC}$ & $\times \mathrm{AC}$ \\
\hline $\mathrm{CNB}$ & BT18-034_P2_01Aug18_012 & $\mathrm{CNB}$ & $\mathrm{CNB}$ \\
\hline CNS & BT18-037_P2_02Aug18_009 & $\times \mathrm{CG}$ & $\checkmark \mathrm{CNS}$ \\
\hline $\mathrm{CN}$ & BT18-051_P2_07Aug18_003 & $\times \mathrm{HD}$ & $\times \mathrm{CNB}$ \\
\hline CNS & BT18-059_P22_09Aug18_003 & $\times \mathrm{CG}$ & $\checkmark \mathrm{CNS}$ \\
\hline CNS & BT18-064_P22_23Aug18_006 & x HD & $x \mathrm{HD}$ \\
\hline $\mathrm{CNB}$ & BT18-065_P22_14Aug18_009 & $\mathrm{CNB}$ & $\mathrm{CNB}$ \\
\hline CNS & BT18-071_P22_15Aug18_003 & × Unknown & × Unknown \\
\hline $\mathrm{CNB}$ & BT18-073_P22_16Aug18_009 & $\mathrm{CNB}$ & $\mathrm{CNB}$ \\
\hline $\mathrm{CN}$ & BT18-075_P22_16Aug18_003 & × Unknown & $\times \mathrm{CNB}$ \\
\hline $\mathrm{CNB}$ & BT18-078_P22_17Aug18_012 & $\mathrm{CNB}$ & $\mathrm{CNB}$ \\
\hline $\mathrm{CN}$ & BT18-086_P22_21Aug18_012 & × Unknown & $\times \mathrm{CNB}$ \\
\hline $\mathrm{CNB}$ & BT18-089_P22_24Aug18_009 & $\mathrm{CNB}$ & $\mathrm{CNB}$ \\
\hline
\end{tabular}




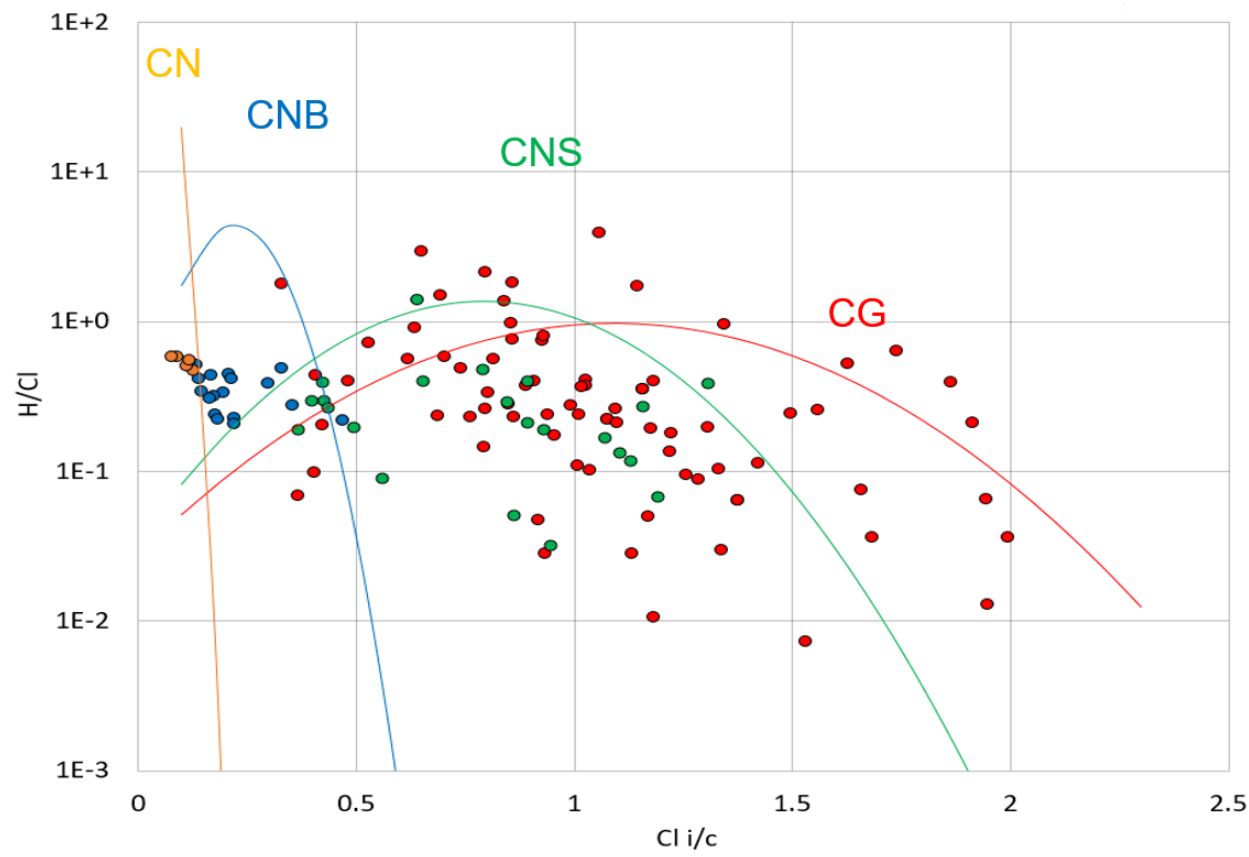

Figure 1. 2-D plot of $\mathrm{H} / \mathrm{Cl}$ vs. $\mathrm{Cl}$ i/c ratios of $\mathrm{CN}$ (orange circles), $\mathrm{CNB}$ (blue circles), CNS (green circles) and CG (red circles) from a collection of PINS-CF data. $\mathrm{Cl} \mathrm{i} / \mathrm{c}$ ratio values of each chemical agent was fitted with a 1-D normalized Gaussian distribution. It should be noted that there is significant overlap between CNS and CG while CN and CNB are relatively well isolated.

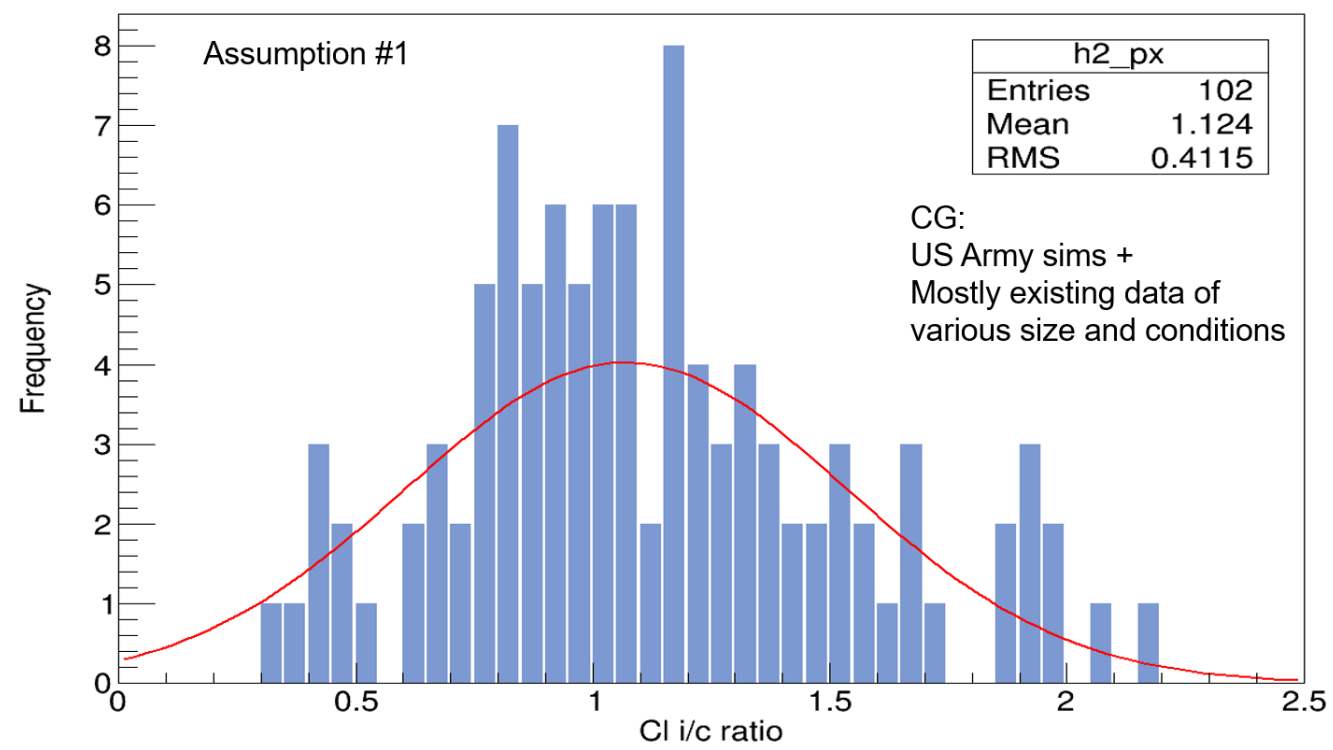

Figure 2. $\mathrm{Cl}$ i/c ratio values fitted with a normalized Gaussian distribution. $\mathrm{Cl} \mathrm{i} / \mathrm{c}$ ratio values are assumed to follow a Gaussian distribution (red line) in this study. More data from the field operations would be beneficial to build a larger population to reveal their true distribution in the future. The same Gaussian fittings were performed on CN, CNB and CNS data, respectively. 


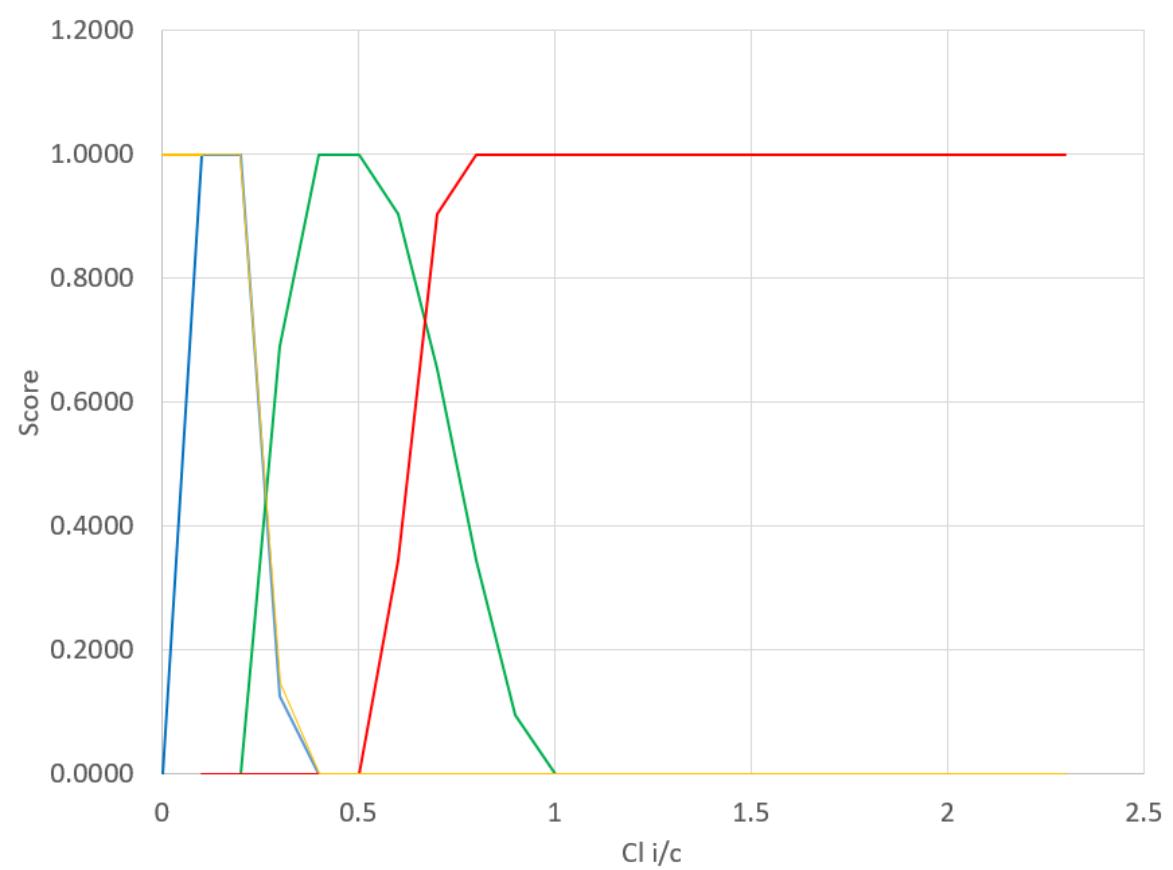

Figure 3. Current PINS-CF Cl i/c ratio indicator functions for CN (orange), CNB (blue), CNS (green) and CG (red), using the indicator function as defined in Eq. (1).

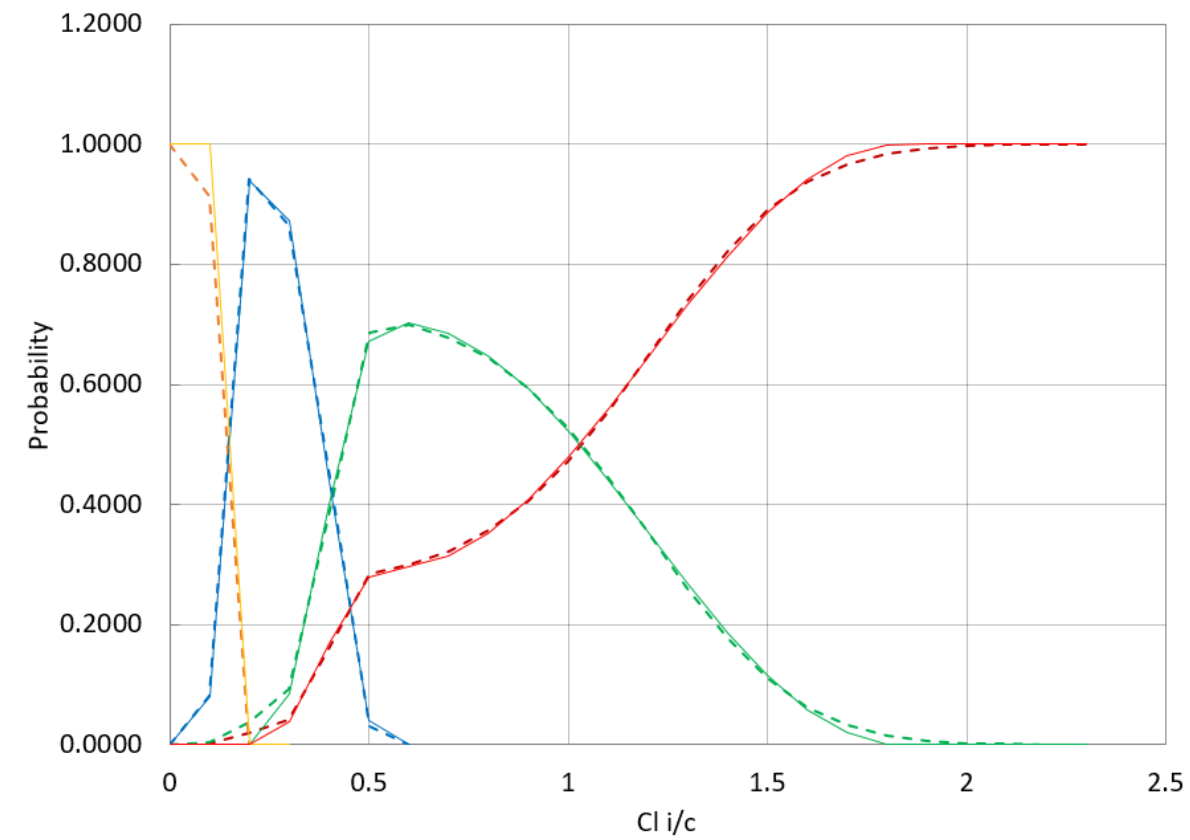

Figure 4. Newly proposed PINS-CF system's $\mathrm{Cl}$ i/c ratio indicator functions for $\mathrm{CN}$ (orange), CNB (blue), CNS (green) and CG (red) with equal prior probabilities, $[P(C N): P(C N B): P(C N S): P(C G)]=$ $[0.25: 0.25: 0.25: 0.25]$. The dotted lines are from the analytical functions while the solid lines are from the approximated ones as defined in Eq. (3). 


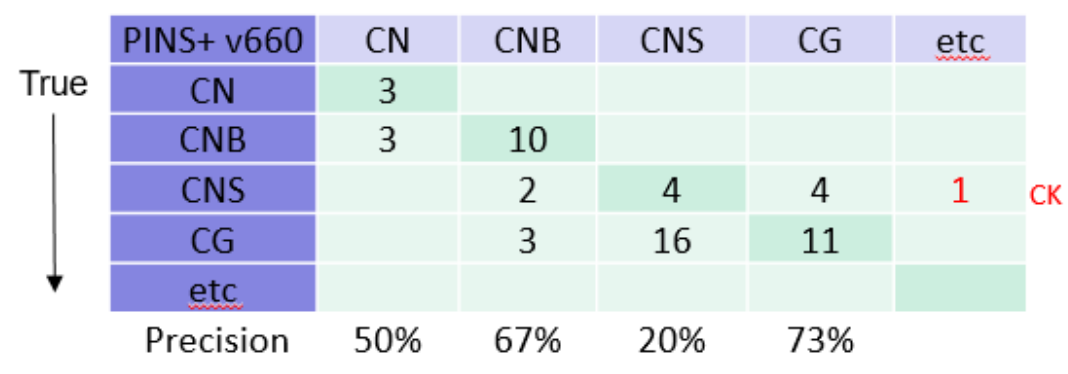

\begin{tabular}{|c|c|c|c|c|c|c|}
\hline \multirow[t]{2}{*}{$P(C W A)$} & 0.25 & 0.25 & 0.25 & 0.25 & & \multirow{8}{*}{$\begin{array}{l}\text { unknown } \\
1 \text { CK } 4 \text { Unknown }\end{array}$} \\
\hline & $\mathrm{CN}$ & CNB & CNS & CG & etc & \\
\hline $\mathrm{CN}$ & 3 & & & & & \\
\hline CNB & & 12 & 1 & & & \\
\hline CNS & & & 8 & 2 & 1 & \\
\hline CG & & & 13 & 12 & 5 & \\
\hline \multicolumn{6}{|l|}{ etc } & \\
\hline Precision & $100 \%$ & $100 \%$ & $38 \%$ & $86 \%$ & & \\
\hline
\end{tabular}

\begin{tabular}{|c|c|c|c|c|c|c|}
\hline P(CWA & 0.10 & 0.20 & 0.30 & 0.40 & & \\
\hline & CN & CNB & CNS & CG & etc & \multirow{2}{*}{ Predicted } \\
\hline CN & 3 & & & & & \\
\hline CNB & & 12 & 1 & & & \\
\hline CNS & & & 7 & 2 & 2 & 1 CK 1 Unknown \\
\hline CG & & & 10 & 15 & 5 & 2 CK 3 Unknown \\
\hline etc & & & & & & \\
\hline Precision & $100 \%$ & $100 \%$ & $41 \%$ & $88 \%$ & & \\
\hline
\end{tabular}

\begin{tabular}{|c|c|c|c|c|c|c|}
\hline \multirow[t]{2}{*}{$P(C W A)$} & 0.10 & 0.10 & 0.30 & \multicolumn{2}{|l|}{0.50} & \\
\hline & $\mathrm{CN}$ & CNB & CNS & CG & etc & \\
\hline $\mathrm{CN}$ & 3 & & & & & \\
\hline CNB & & 12 & 1 & & & \\
\hline CNS & & & 4 & 5 & 2 & 1 CK 1 Unknown \\
\hline CG & & & 9 & 16 & 5 & 2 CK 3 Unknown \\
\hline etc & & & & & & \\
\hline Precision & $100 \%$ & $100 \%$ & $31 \%$ & $76 \%$ & & \\
\hline
\end{tabular}

Figure 5. Three different sets of prior probabilities for $\mathrm{CN}, \mathrm{CNB}, \mathrm{CNS}$ and $\mathrm{CG}$ were tested with a collection of 57 spectra. The first table shows the results from PINS+ v6.6.0 with current PINS-CF formulae in comparison to ones with new $\mathrm{Cl}$ i/c ratio indicator functions. The best performing set of prior probabilities is $[P(C N): P(C N B): P(C N S): P(C G)]=[0.10: 0.20: 0.30: 0.40]$ with the highest precisions for all four chemical agents. 


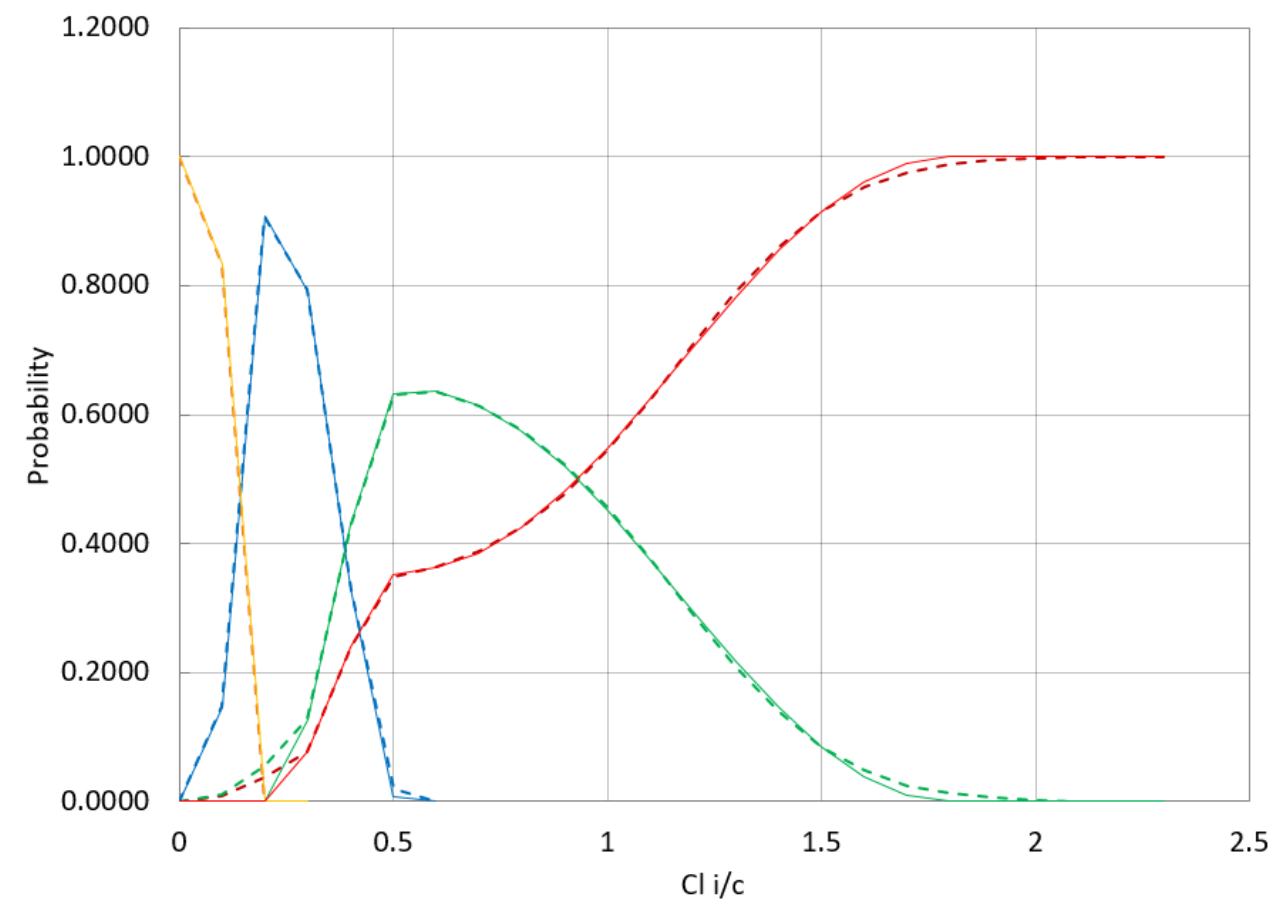

Figure 6. Newly proposed PINS-CF system's $\mathrm{Cl}$ i/c ratio indicator functions for CN (orange), CNB (blue), CNS (green) and CG (red) with the optimal prior probabilities, $[\mathrm{P}(\mathrm{CN}): \mathrm{P}(\mathrm{CNB}): \mathrm{P}(\mathrm{CNS}): \mathrm{P}(\mathrm{CG})]$ $=[0.10: 0.20: 0.30: 0.40]$. The dotted lines are from the analytical functions while the solid lines are from the approximated ones as defined in Eq. (4).

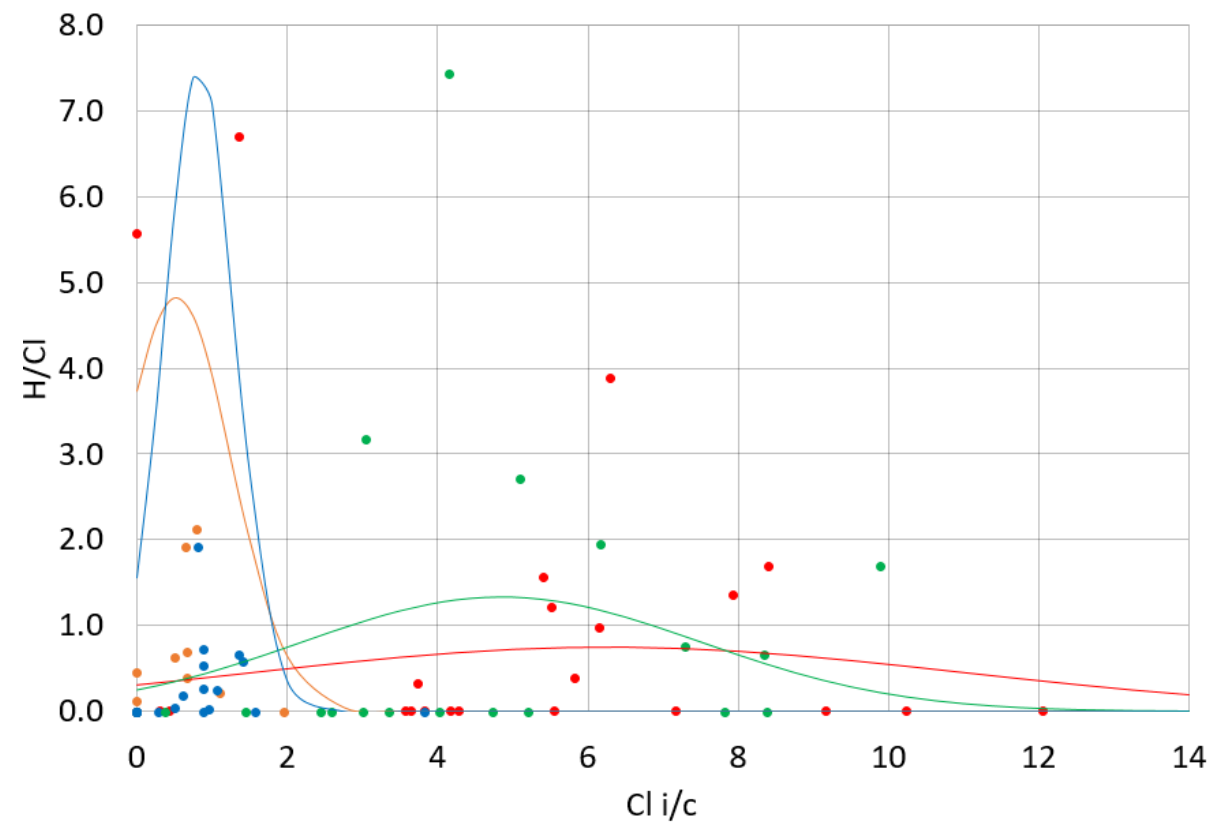

Figure 7. 2-D plot of $\mathrm{H} / \mathrm{Cl}$ vs. $\mathrm{Cl}$ i/c ratios of $\mathrm{CN}$ (orange circles), $\mathrm{CNB}$ (blue circles), CNS (green circles) and CG (red circles) from a collection of PINS-DT data. $\mathrm{Cl}$ i/c ratio values of each chemical agent was fitted with a 1-D normalized Gaussian distribution. It should be noted that there is significant overlap between CNS and CG while CN and CNB are relatively well isolated. 


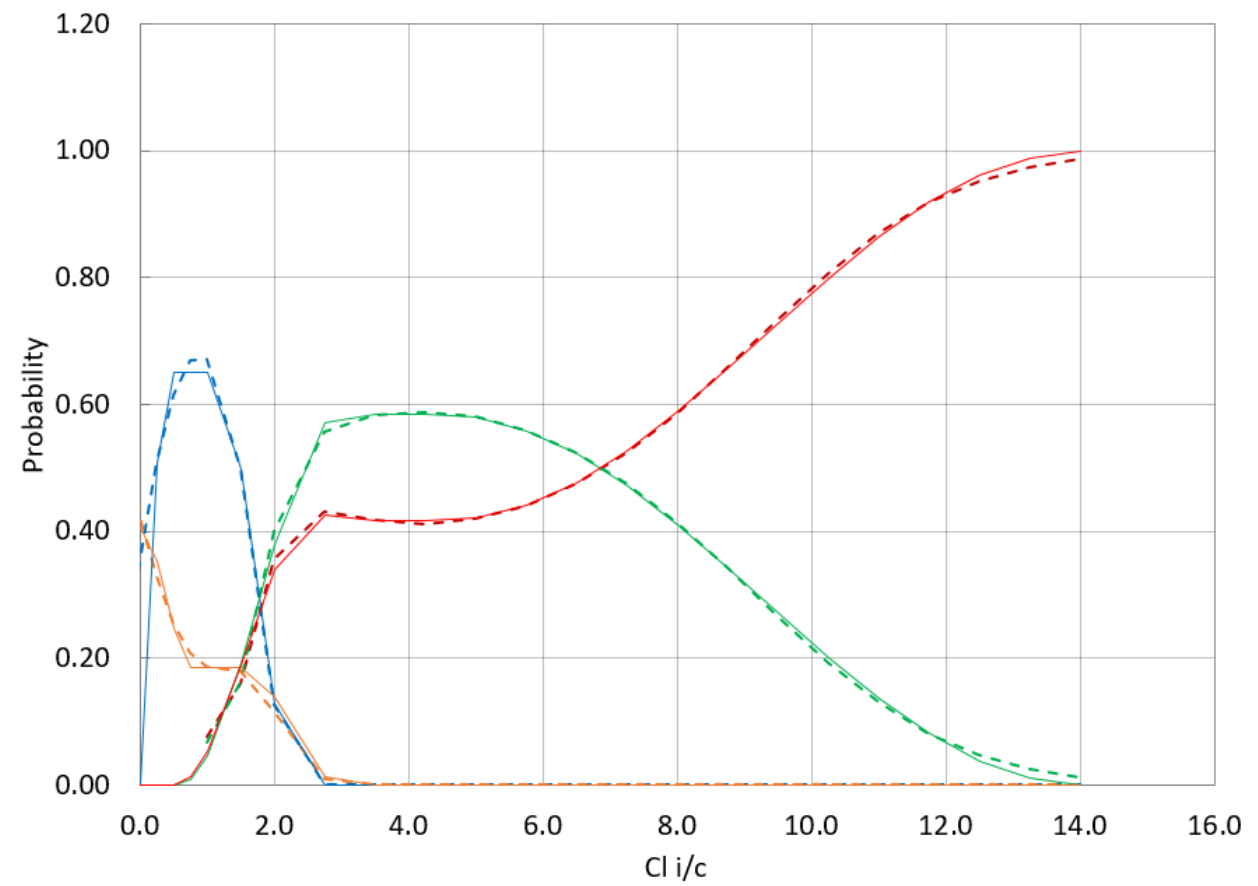

Figure 8. Newly proposed PINS-DT system's $\mathrm{Cl}$ i/c ratio indicator functions for CN (orange), CNB (blue), CNS (green) and CG (red) with the optimal prior probabilities, $[\mathrm{P}(\mathrm{CN}): \mathrm{P}(\mathrm{CNB}): \mathrm{P}(\mathrm{CNS}): \mathrm{P}(\mathrm{CG})]$ $=[0.10: 0.20: 0.30: 0.40]$. The dotted lines are from the analytical functions while the solid lines are from the approximated ones as defined in Eq. (5). 